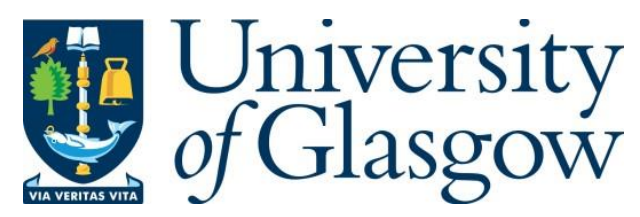

Giugliano, D., Barbera, D. and Chen, H. (2017) Effect of fiber cross section geometry on cyclic plastic behavior of continuous fiber reinforced aluminum matrix composites. European Journal of Mechanics - A/Solids, 61, pp. 35-46.

There may be differences between this version and the published version. You are advised to consult the publisher's version if you wish to cite from it.

http://eprints.gla.ac.uk/153004/

Deposited on: 5 December 2017

Enlighten - Research publications by members of the University of Glasgow http://eprints.gla.ac.uk 


\title{
EFFECT OF FIBER CROSS SECTION GEOMETRY ON CYCLIC PLASTIC BEHAVIOR OF CONTINUOUS FIBER REINFORCED ALUMINUM MATRIX COMPOSITES
}

\author{
Dario Giugliano, Daniele Barbera, Haofeng Chen* \\ Department of Mechanical and Aerospace Engineering, University of Strathclyde \\ Glasgow, G1 1XJ, United Kingdom \\ *Email: Haofeng.chen@,strath.ac.uk, web page: http://www.strath.ac.uk
}

\begin{abstract}
This paper investigates the cyclic plastic behavior of continuous fiber-reinforced aluminum matrix composites (CFAMCs) with different shape of fiber cross section arranged in a square packing geometry. The 2D micromechanical FEM models, composed of elastic undamaged reinforcement perfectly bonded to an elastic-perfectly plastic matrix with a volume fraction equal to $30 \%$, are subjected to off-axis constant macro stress and a cyclic temperature history. Under such load conditions, the matrix undergoes large internal inelastic deformations potentially leading to internal crack initiation as well as macroscopic ratcheting. The computational method, the Linear Matching Method (LMM), is used throughout the analysis for the direct evaluation of shakedown, alternating plasticity and ratcheting behaviors. The effect of the matrix yield stress thermal degradation upon two common design limits, i.e., the reverse plasticity limit and the ratchet limit, is also investigated and discussed, including its influence on the off-axis low cycle fatigue crack initiation.
\end{abstract}

Keywords: Shakedown, Cyclic Plasticity, Metal Matrix Composite.

\section{INTRODUCTION}

The cyclic (Han et al., 1995; Llorca, 1994; Sasaki et al., 1994) and monotonic (Corbin and Wilkinson, 1994; Llorca et al., 1991; Llorca et al., 1992) mechanical responses of metal matrix composites (MMCs) made up of a metal matrix and ceramic reinforcement have been much studied both numerically and experimentally in the literature. The compelling attention on such materials is due to their excellent combination of low density, high tensile strength, enhanced stiffness, high operating temperatures, wear and creep properties compared with the monolithic metallic counterpart (Suresh et al., 1993).

Continuous fiber-reinforced aluminum matrix composites (CFAMCs) are currently being used in many automotive and aerospace applications such as automotive push rods, brake calipers, retainer rings and flywheels for energy storage, etc., which are often subjected to a combination of static and cyclic conditions (Surappa, 2003). It is well know that the main factors that influence the mechanical response of a general MMC are the mechanical properties of the constituents, the fiber arrangement, the reinforcement fraction volume and its shape (Böhm et al., 1993; Devireddy and Biswas, 2014; Giugliano and Chen, 2016; Hashin, 1983; Srivastava et al., 2011; Xu et al., 1999). The fatigue behavior of MMCs has also been investigated by many researchers with emphasis on the crack propagation rates and low cycle fatigue response under both thermal fatigue and thermo mechanical fatigue. It has been demonstrated that introducing hard ceramic particles in a metallic matrix, the crack propagation rate becomes lower than its unreinforced counterpart (Bonnen et al., 1990). However the existence of the reinforcement in MMCs dramatically reduces the low cycle fatigue (LCF) response of both particulate and fiber reinforced MMCs subjected to off-axis constant macro stress and thermal cyclic conditions (Chen and Ponter, 2005; Giugliano and Chen, 2016; Jansson and 
Leckie, 1992). It has also been reported that an increase in either fiber volume fraction or particle volume fraction causes further degradation of the LCF response (Giugliano and Chen, 2016; Srivatsan and Auradkar, 1992; Srivatsan and Prakash, 1994). Such a reduction, is mainly due to the mismatch in the thermal expansion coefficient (CTE) of the constituents, the stress concentration at the constituent's interface, the brittle nature of the ceramic reinforcement and the plastic flow constraint within the metallic matrix (Giugliano and Chen, 2016; Jansson and Leckie, 1992; Llorca, 1994; Srivatsan and Prakash, 1994; Uygur and Külekci, 2002).

So far, there have been a number of experimental and numerical studies on the cyclic plastic behavior to characterize the inelastic response of MMCs but, to the best of authors' knowledge, there has been no study concerning the effect of fiber cross section geometry on the cyclic plastic behavior of CFAMCs although a deep study on the effect of particulate shape on the cyclic deformation of $\mathrm{SiC}_{\mathrm{p}} / 6061 \mathrm{Al}$ composites has been reported in (Kang et al., 2007). Thus an investigation of the inelastic response under the combined action of cyclic thermal conditions and off-axis constant macro stress has been carried out numerically using the Linear Matching Methods (LMMs) (Chen, 2010; Chen and Ponter, 2010). Any structure, including composites, that undergo cyclic conditions, can exhibit elastic behavior, shakedown, reverse plasticity or ratcheting depending upon the applied load level. The evaluation of these patterns of behavior may be obtained through a large number of step by step finite element calculations. However, such a numerical procedure can be difficult, very timeconsuming and essentially subjective because it depends strongly on the choice of the loading conditions. The latest development of the LMM makes it possible to identify the primary characteristics of the load domain boundaries accurately and efficiently to determine various responses and mechanisms. Indeed, a wide range of applications involving the evaluation of high temperature response of the structures subjected to a cyclic load history have been examined by the LMMs (Chen, 2010; Lytwyn et al., 2015; Ure et al., 2013), for the direct calculation of the limit load, reverse plasticity limit and ratchet limit as well as for the comprehensive explanation of the low cycle fatigue behavior. Among them, the LMMs have been adopted to investigate the cyclic plastic response of particulate reinforced $\mathrm{AMC}$ and fiber reinforced AMC under cyclic temperature and constant stress (Chen and Ponter, 2005; Giugliano and Chen, 2016).

The main objective of this study is to investigate the effects of different cross section geometries of fiber on the cyclic plastic responses of AMCs using the LMMs and by micromechanical finite element models. The crucial aspect of matrix yield stress thermal degradation, on the critical design limits, is also considered. An aluminum alloy matrix (Al $2024 \mathrm{~T} 3$ ) reinforced with $30 \%$ of alumina $\left(\mathrm{Al}_{2} \mathrm{O}_{3}\right)$ has been employed throughout the numerical procedure for the direct evaluation of limit load, reverse plasticity limit and ratchet limit. Incremental FEA (step-by-step analysis) has been carried out by Abaqus (Hibbitt, 1997) in order to validate the LMM's results.

The relevant LMM numerical approach and the problem definition have already been presented in our companion paper (Giugliano and Chen, 2016) which characterize the cyclic plastic behavior of CFAMCs with circular cross section and different fiber volume fractions. The iterative method for calculating the shakedown and ratchet limit has been widely described in (Chen, 2010; Chen and Ponter, 2010). Therefore this paper prefers to present a summary of the LMM framework and its software tool, rather than the detailed numerical procedures for both shakedown and ratchet analyses.

\section{THE LINEAR MATCHING METHOD FRAMEWORK AND ITS SOFTWARE TOOL}

The LMMF is composed by a solid and robust series of FORTRAN subroutines which are used to solve, within an iterative procedure, several practical problems where the residual stress field caused by the cyclic loading history is either constant or changing. This iterative procedure adopts a number 
of linear analyses to simulate nonlinear behavior of the material, using a changing shear modulus that varies with both time and space.

The LMMF also provides an efficient Direct Steady Cycle Analysis (DSCA) method. It is capable of evaluating, in a very accurate way, the saturated cycle of a structure subjected to a cyclic load. By accurately evaluating the steady state cycle, the LCF life can be investigated. It is worth mentioning that the DSCA has been extended recently to consider the effect of creep dwell on the steady state response. By adopting the extended DSCA analysis, many crucial parameters for the creep fatigue damage assessment can be identified. Among all the most important key parameters are the stress at the start of the creep dwell, the creep strain increment, the related elastic follow-up factor and the total strain range during the load cycle. All these quantities are calculated considering the full creep fatigue interaction rather than considering conservative assumptions. Due to all these features the LMMF is becoming an efficient and versatile tool for the structural and integrity assessment of simple and complex structures.

The LMMF also includes a robust software tool with a Graphical User Interface (GUI) developed recently by (Ure et al., 2012) to perform all the numerical analyses without having to manipulate the FORTRAN subroutines directly (Chen et al., 2014; Ure et al., 2014). Since at the initial development stage of the LMM, all the efforts were on the user subroutine development, rather than the user friendliness, this strategy leads to the difficulty of disseminating the method to a wider range of users. Indeed, the user is obliged to directly manipulate and modify the FORTRAN source code, to perform even a simple shakedown analysis. The definition of the load cycle, the selection of the material parameters, the element number and the element type in FORTRAN subroutines, are not intuitive for users without any programming experience, leading to mistakes that may invalidate the analysis. For these reasons an Abaqus plug-in software tool has been developed, to simplify the analysis definition, and improve the robustness of the LMM calculations.

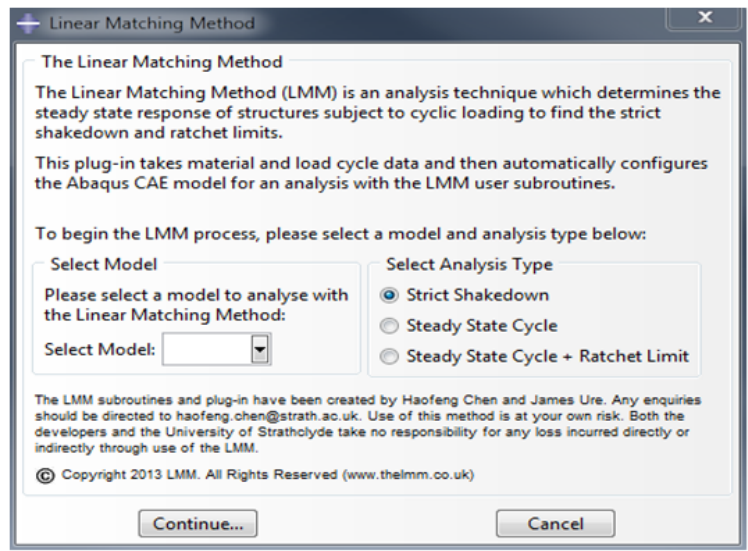

(a)

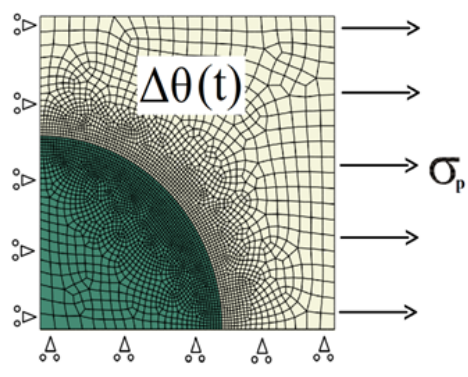

(c)

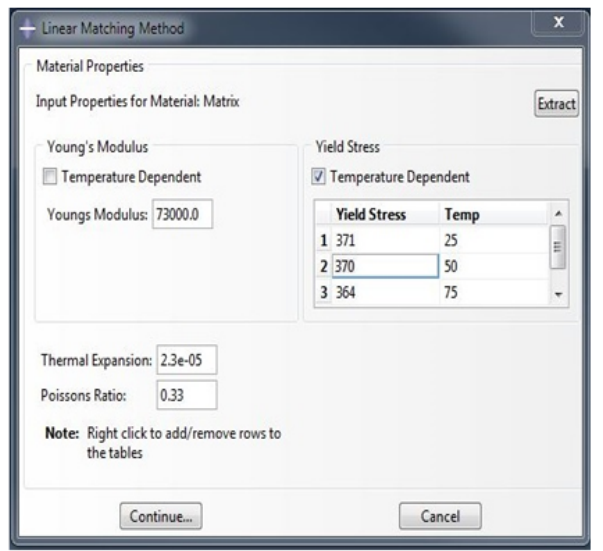

(b)

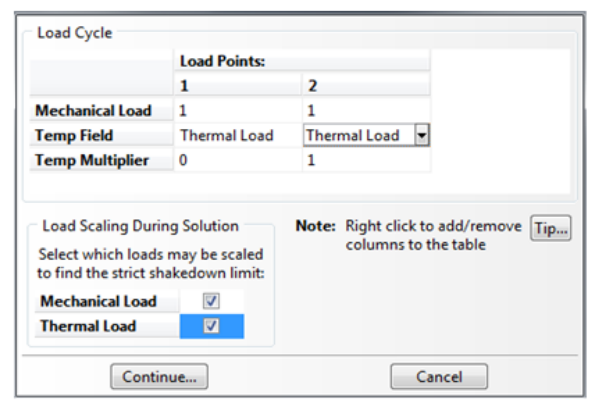

(d)

Fig. 1. a) LMM main menu for analysis type and model selection; b) material properties selection; c) CAE model with reference loads, d) Load cycle dialog and load scaling options. 
The analysis type and the existing model can be selected through a GUI as shown in Fig. 1-a. The material properties can be automatically extracted from the Abaqus CAE or introduced by the user (Fig. 1-b). A python code within the plug-in verifies that each value provided is reasonable. One of the most useful improvements given by the LMM plugin regards the load cycle definition shown in Fig. 1-d, where multiple load points can be created by using individual loads or temperature fields previously defined in the CAE (Fig. 1-c). This approach allows the user to consider a whole class of different cyclic loading conditions.

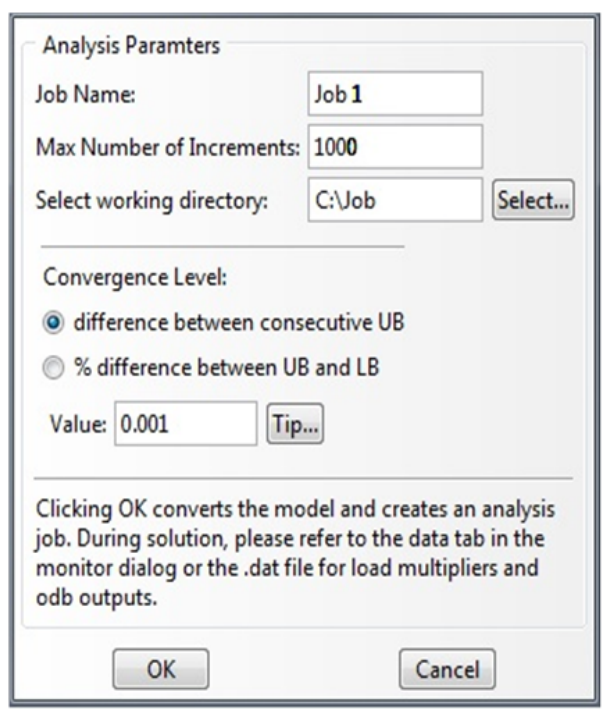

(a)

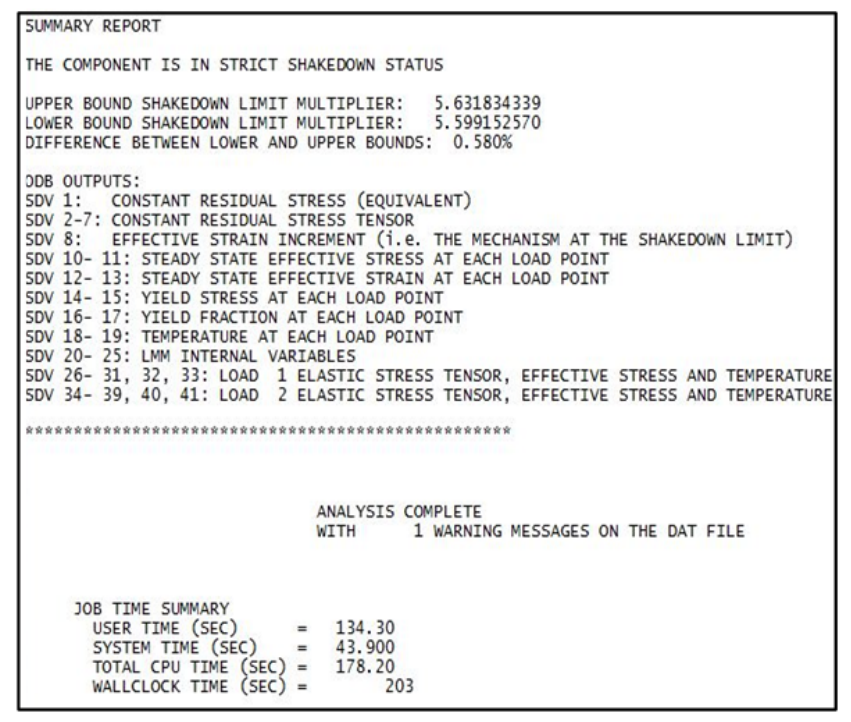

(b)

Fig. 2. a) Analysis parameters, convergence methods and level menu; b) LMM summary report.

The desired convergence rule ensures the estimation of the numerical solution within a prespecified tolerance value (Fig. 2-a). The first rule is based on the difference between each consecutive upper bound and the analysis ends when for five consecutive iterations the difference is lower than the provided value. The second one considers the difference between the upper bound and lower bound. When the desired difference level is achieved, the analysis terminates.

A LMM job is like other standard Abaqus jobs which call user subroutines. While solving a LMM job, the progress of the solution may be seen in the "Monitor" dialog box. Information such as the current step and increment is displayed along with any warnings and errors encountered. During the calculation, both the lower and upper bound load multipliers and convergence levels are printed for the current increment so the user can see the progress of the solution. When the analysis is complete a summary is printed which declares the shakedown status of the model, the corresponding shakedown or ratchet limits and a list of the State Dependent Variable (SDV) definition so the user can view contour plots of the results. A sample summary given in the Monitor dialog box, for a shakedown analysis, is shown in Fig. 2-b. For the ratchet analysis, further variables are available. Along with stress, strain and residual stress field already displayed in Fig. 2-b, there are maximum plastic strain range $\Delta \bar{\varepsilon}_{p_{\max }}$ and ratcheting strain per cycle $\Delta \bar{\varepsilon}_{r t c}$. The former is related to the low cycle fatigue life, the latter to the incremental plastic collapse.

It is worth noting that the LMM software tool has the capability to perform multiple Computer Processing Units (CPUs) analysis. This feature is very important for the large model when complex 3D geometries are considered. 


\section{PROBLEM DESCRIPTION AND FINITE ELEMENT MODELS}

Within this paper discussion, micromechanical finite element models are adopted to simulate both the static and cyclic plastic response of CFAMCs. A comprehensive study of the shakedown, alternating plasticity and ratcheting behaviors aimed at evaluating the effects of fiber cross section geometry along with the thermal degradation of matrix yield stress $\sigma_{y}$ on two critical design limits, i.e., the reverse plasticity limit $\Delta \theta_{r p}$ and the ratchet limit $\Delta \theta_{r t c}$ has been undertaken using the Linear Matching Method.

Table 1

Material properties.

\begin{tabular}{ccc}
\hline Material Property & $\mathbf{A l 2 0 2 4} \mathbf{~ T 3}$ & $\mathbf{A l}_{\mathbf{2}} \mathbf{O}_{\mathbf{3}}$ \\
\hline Young's Modulus [MPa] & 73 & 370 \\
Coefficient of thermal expansion $\left[\mathrm{MK}^{-1}\right]$ & 23 & 8 \\
Yield stress [MPa] & $*$ & 5000 \\
Poisson's ratio & 0.33 & 0.26 \\
\hline
\end{tabular}

Table 2

Temperature dependent yield stress.

\begin{tabular}{cccccccccccc}
\hline $\mathrm{T}\left[{ }^{\circ} \mathrm{C}\right]$ & 25 & 50 & 75 & 100 & 125 & 150 & 175 & 200 & 275 & 300 & 400 \\
$* \sigma_{y}(\mathrm{~T})$ & 371 & 364 & 358 & 351 & 345 & 338 & 331 & 325 & 305 & 298 & 272 \\
\hline
\end{tabular}
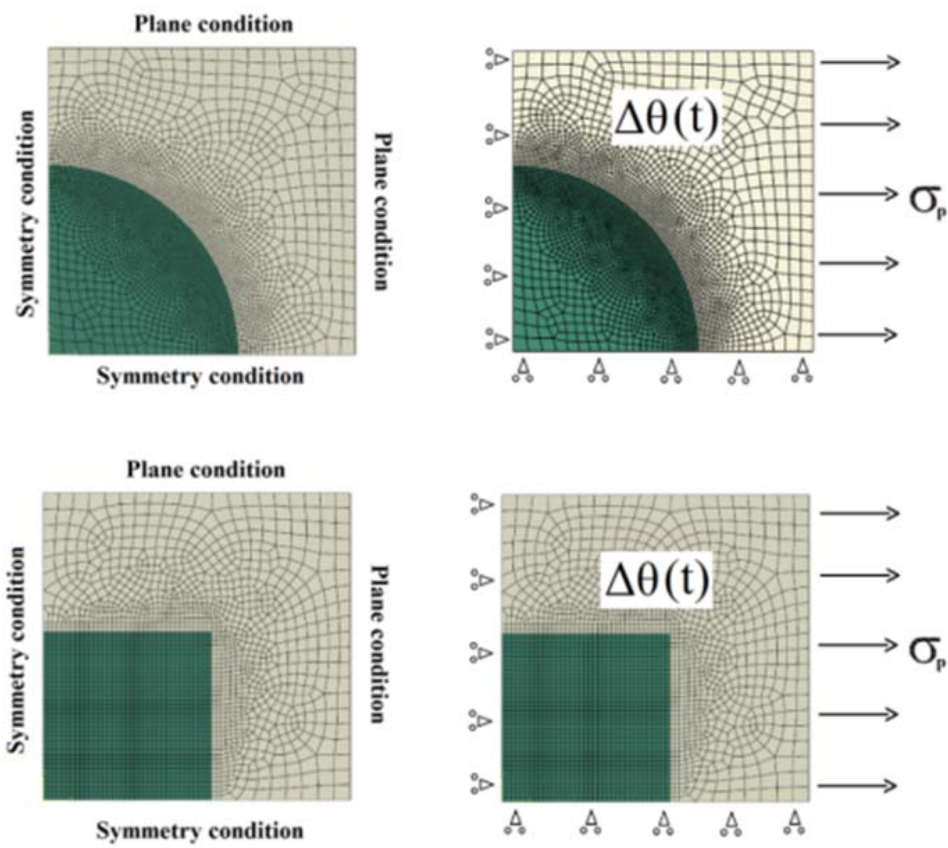

(a)

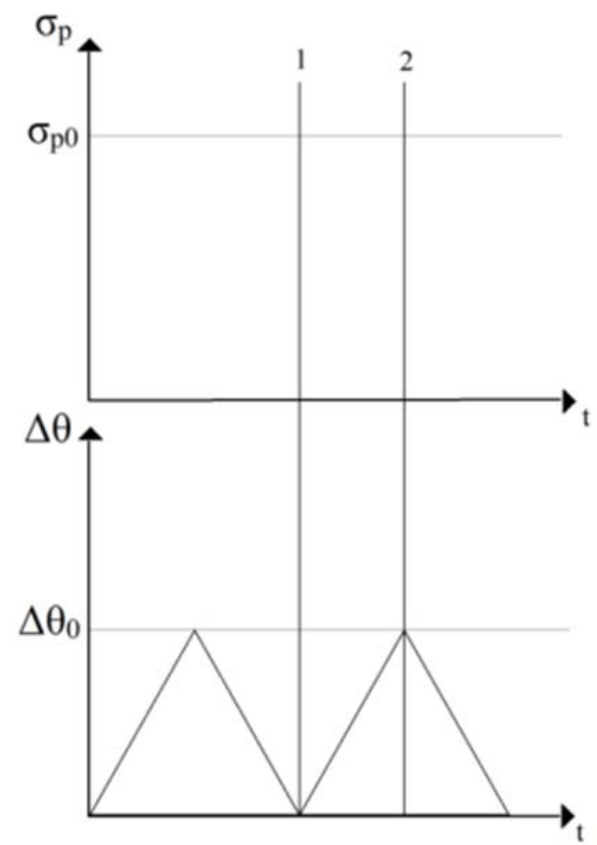

(b)

Fig. 3. a) A quarter of the RVEs concerning the reference models; b) Applied cyclic loading. 


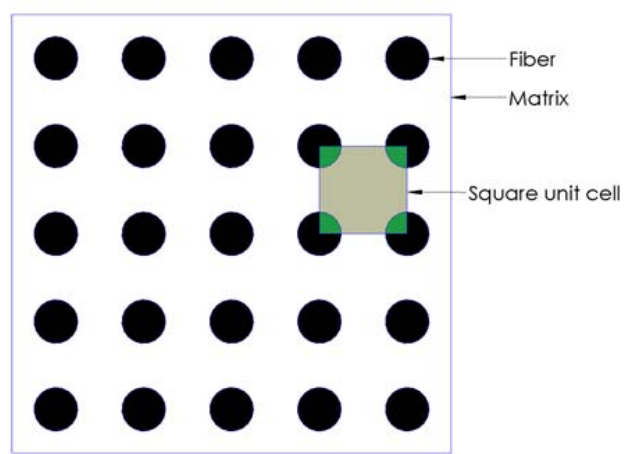

(a)

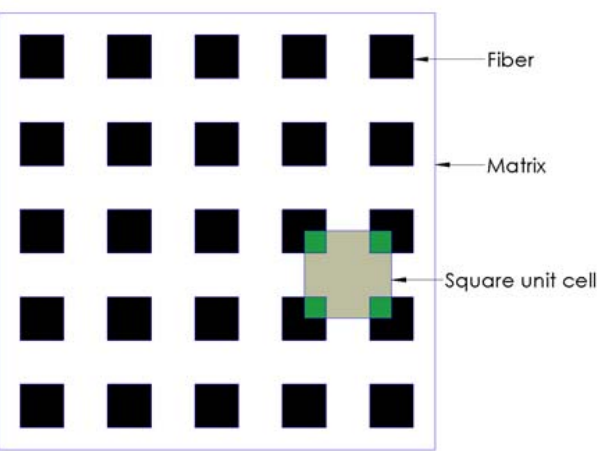

(b)

Fig. 4. a) Square array with circular fibers; b) square array with square fibers.

An Al 2024-T3 alloy reinforced with $30 \% \mathrm{Al}_{2} \mathrm{O}_{3}$ is considered (Table 1 and Table 2). An Elastic Perfectly Plastic (EPP) constitutive model is used for the former while an isotropic perfectly elastic material simulates the fiber. A 2D micromechanical representative volume element (RVE) is adopted to numerically simulate the MMC behavior. Fig. 3 depicts the two reference models arranged with a square packing geometry as shown in Fig. 4. Since the unidirectional fiber reinforced composites can be treated as plane strain case, all degrees of freedoms in the fiber direction are fixed, i.e. there is no displacement deformation in the fiber direction. Therefore quadrilateral plane strain elements have been used for the mesh scheme of the unit cells.

A uniaxial macro-stress $\sigma_{P}$ acts in a direction perpendicular to opposing faces of the unit cells and is maintained constant while a cyclic temperature field is applied uniformly over the unit cells, with varying range 0 to $\Delta \theta$ (Fig. 3-a, b). The FE models are subjected to homogeneous boundary conditions so that the surface displacement in a single unit cell is consistent with that of adjacent identical cells within the RVE. Since the boundary condition problem described is a stress approach problem, beside the uniform macro-stress $\sigma_{P}$ imposed on the boundary, plane conditions are applied (Fig. 3-a) by Abaqus constraint equations in order to maintain the periodic deformation (Chen and Hachemi, 2014).
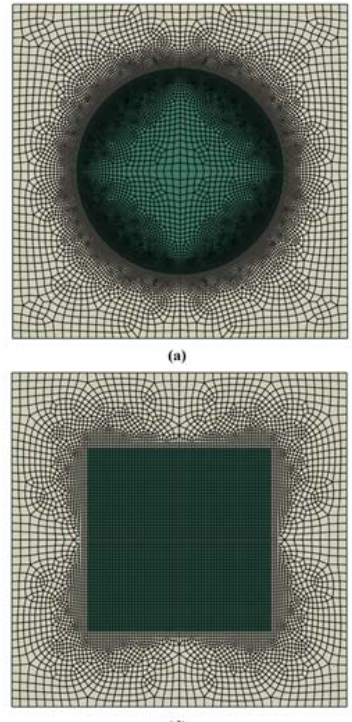
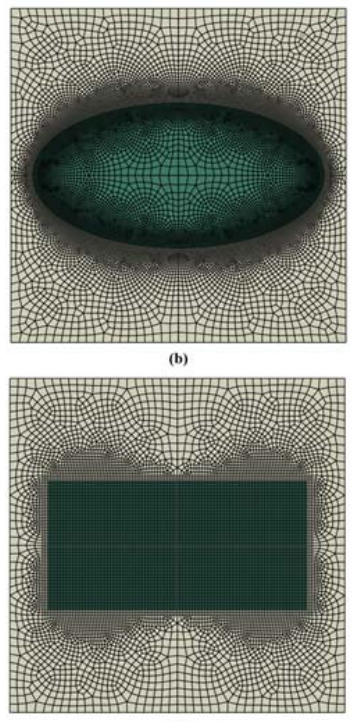
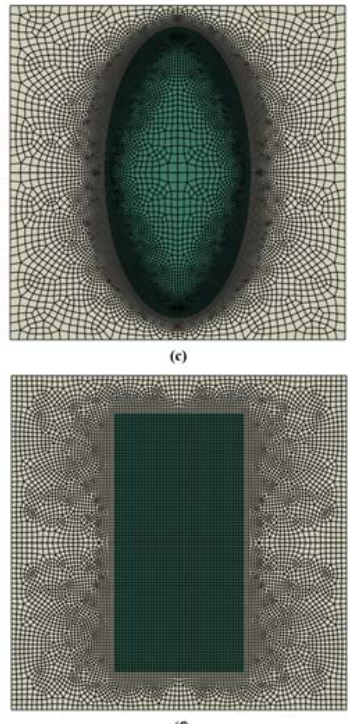

Fig. 5. Fiber cross sections analyzed with $V f=30 \%$ a) Circular cross section, b) Elliptical cross section 1:2, c) Elliptical cross section 2:1, d) Square cross section, e) Rectangular cross section 1:2, f) Rectangular cross section 2:1. 
A total of six unit cells, with different cross section geometries of the fiber are investigated throughout this paper and are shown in Fig. 5. Fig. 5-a and Fig. 5-d depict the two reference models already shown in Fig. 3 whilst Fig. 5-b, Fig. 5-c, Fig. 5-e and Fig. 5-f depict two different crosssectional aspect ratios. It is worth noting that the chosen value $V f=30 \%$ relies upon the geometrical limitation of the elliptical cross section. Indeed as the defined length of semi-minor axis of the ellipse is half the length of semi-major axis, the theoretical maximum value of $V f$ is equal to $39.27 \%$. Hence a reasonable value of fiber volume fraction adopted for this investigation is $V f=30 \%$.

\section{RESULTS AND DISCUSSIONS}

\subsection{Shakedown and Ratchet limit}

The critical design limits mentioned in the previous paragraph, i.e., the reverse plasticity limit $\Delta \theta_{r p}$ and the ratchet limit $\Delta \theta_{r t c}$ have been calculated for each unit cell and the results are provided in the form of interaction diagram. $\Delta \theta_{r p}$ is the maximum of the cyclic thermal load range $\Delta \theta$ above which reverse plasticity occurs whilst $\Delta \theta_{r t c}$ is the maximum of the cyclic thermal load range above which the structure exhibits ratcheting for any constant mechanical load and leads to an incremental plastic collapse (Giugliano and Chen, 2016).

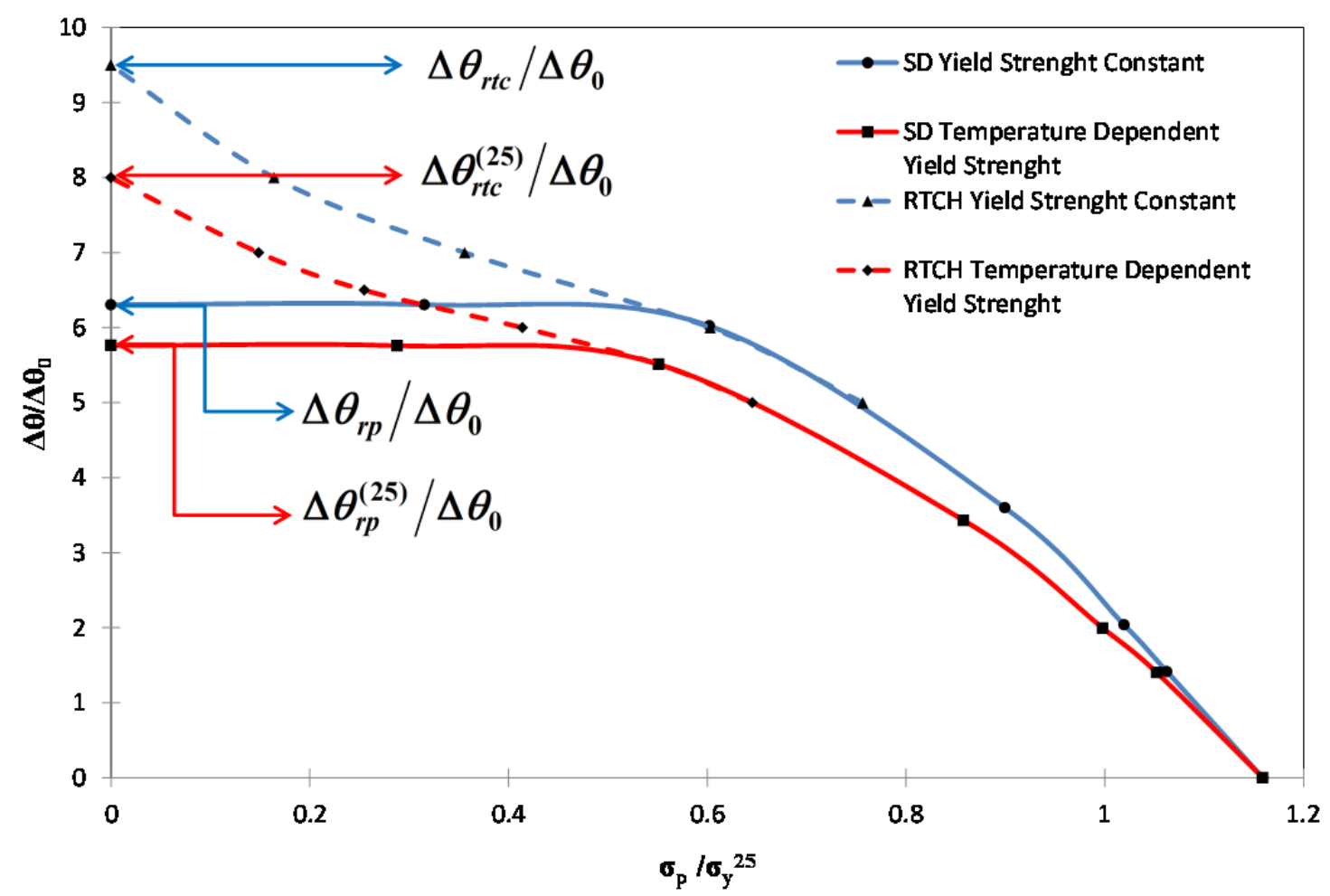

Fig. 6. Comparison between shakedown and ratcheting limit boundaries for the circular model with constant yield stress and temperature dependent yield stress.

In order to evaluate the effect of the matrix yield stress thermal degradation on the inelastic response of CFAMCs, only the circular model has been taken into account. Fig. 6 shows the typical set of shakedown and ratchet limit boundaries in the form of interaction diagram for the circular 
model calculated by the LMM. The axes are expressed in non-dimensional variables $\sigma_{p} / \sigma_{y}^{(25)}$ and $\Delta \theta / \Delta \theta_{0}$ where $\Delta \theta_{0}=50^{\circ} \mathrm{C}$ is the reference thermal load range whilst $\sigma_{y}^{(25)}=371 \mathrm{MPa}$ is the yield stress at $25^{\circ} \mathrm{C}$. As expected, the matrix yield stress thermal degradation, leads to lower values of both shakedown and ratchet limit (Chen, 2010) that are:

$$
\left\{\begin{array}{l}
\Delta \theta_{r p}^{(25)}>\Delta \theta_{r p} \\
\Delta \theta_{r t c}^{(25)}>\Delta \theta_{r t c}
\end{array}\right.
$$

where $\Delta \theta_{r p}^{(25)}$ and $\Delta \theta_{r t c}^{(25)}$ are respectively the reverse plasticity limit and the ratchet limit with $\sigma_{y}=$ $\sigma_{y}^{(25)}$ whilst $\Delta \theta_{r p}$ and $\Delta \theta_{r t c}$ are the reverse plasticity limit and the ratchet limit with $\sigma_{y}=\sigma_{y}(T)$ temperature dependent yield stress.

The impact of temperature over the interaction diagram is remarkable, and must be considered in order to accurately determine the micromechanical response. For this reason all the following results presented are obtained considering temperature dependent yield stress.
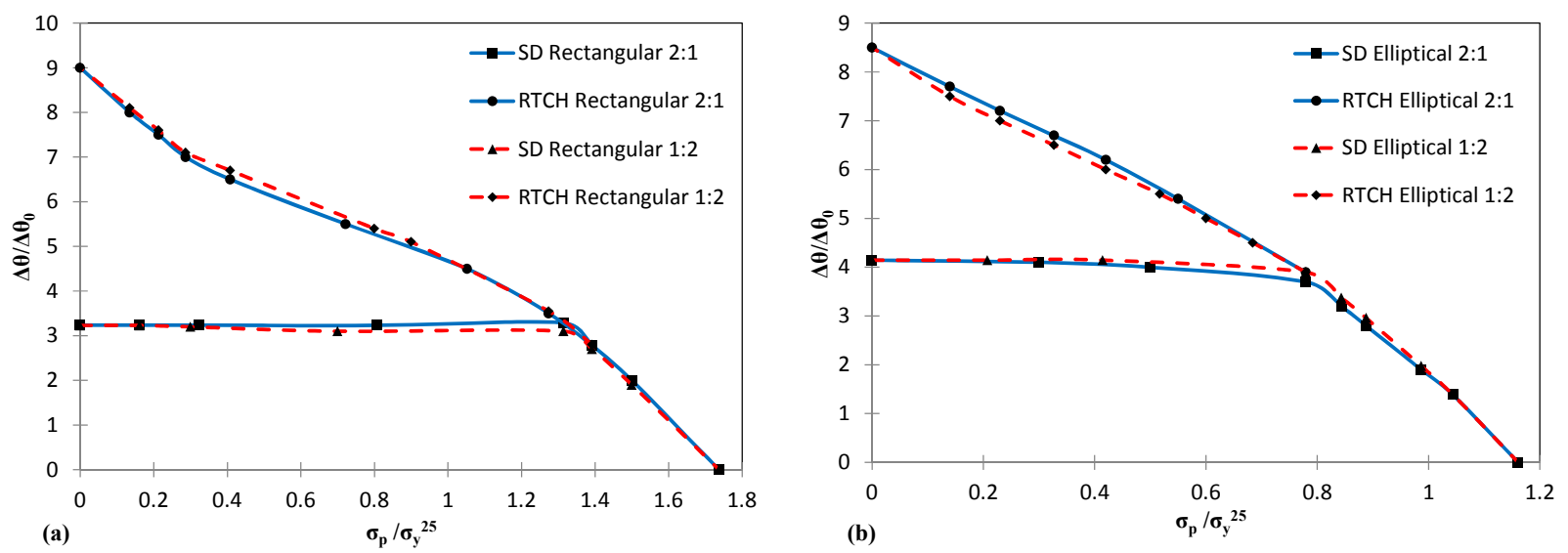

Fig. 7. Comparison between the shakedown and ratchet limit boundaries for $V f=30 \%$ concerning (a) the rectangular model and (b) the elliptical model with aspect ratios 1:2 and 2:1.

Another important outcome is the effect of different aspect ratios on the cyclic response. Fig. 7 shows a comparison between the shakedown and ratchet limit boundaries with regard to the models $b$, c, e and $\mathrm{f}$ depicted in Fig. 5 and distinguished by two aspect ratios, 1:2 and 2:1. It is evident from both Fig. 7-a, related to the models in Fig. 5-e, $\mathbf{f}$ and Fig. 7-b, related to the models in Fig. 5-b, $\mathbf{c}$ that, neglecting the numerical error, the different aspect ratio for $V f=30 \%$ leads to the same results in terms of the interaction diagram. 

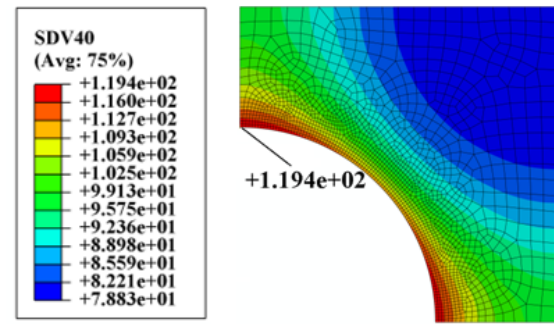

(a)
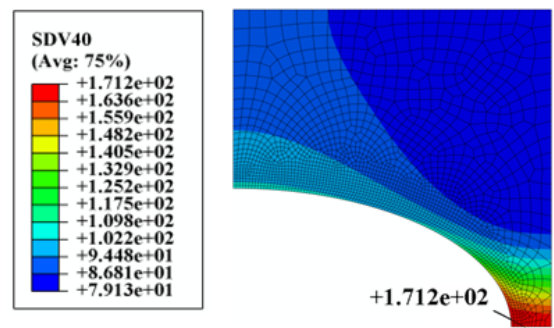

(c)

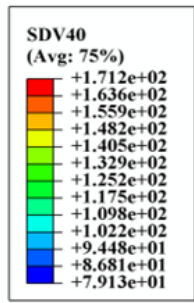

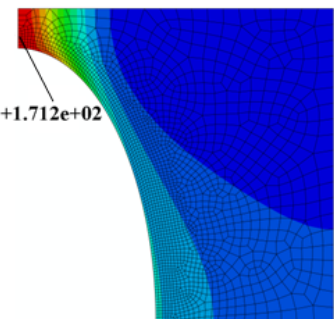

(e)

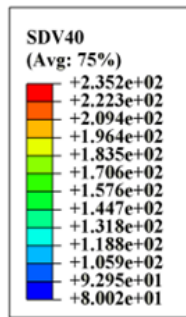

$8.002 \mathrm{e}+0$
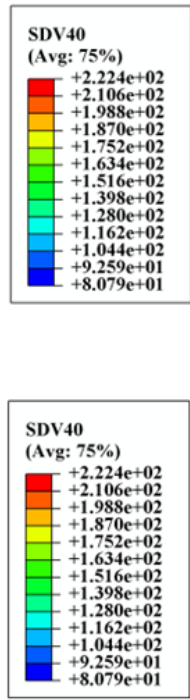

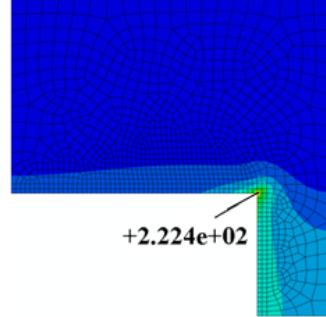

(d)

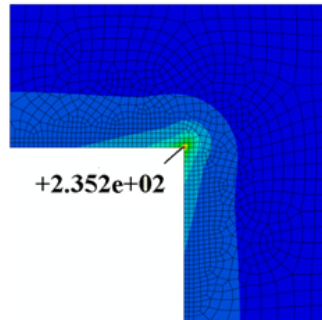

(b)

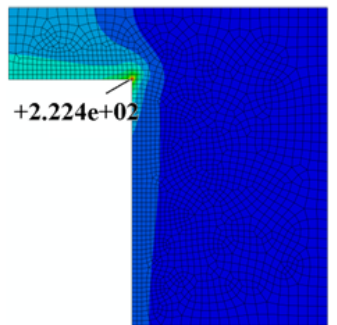

(f)

Fig. 8. Contours of effective thermo-elastic stress under the thermal reference load $\Delta \theta_{0}=50^{\circ} \mathrm{C}$.

Table 3

Effect of fiber cross section geometry on the thermo-elastic stress.

\begin{tabular}{|l|c|c|c|}
\hline $\begin{array}{l}\text { FIBER CROSS } \\
\text { SECTIONS }\end{array}$ & $\boldsymbol{S D V 4 0}_{\text {MAX }}[\mathbf{M P a}]$ & $S A F_{\theta}=S D V 40_{\text {MAX }} / \Delta \theta_{0}\left[\mathbf{M P a} /{ }^{\circ} \mathbf{C}\right]$ & $\Delta \theta_{r p} / \Delta \theta_{0}$ \\
\hline Circular & $1.194 \mathrm{e}+02$ & 2.4 & 5.7 \\
\hline Elliptical & $1.713 \mathrm{e}+02$ & 3.4 & 4.1 \\
\hline Square & $2.352 \mathrm{e}+02$ & 4.7 & 3 \\
\hline Rectangular & $2.224 \mathrm{e}+02$ & 4.4 & 3.2 \\
\hline
\end{tabular}

This unexpected behavior is more evident for the three critical design limits where the computed values are nearly equal. A further discussion on the limit load $\sigma_{P l}$ is given in section 4.3. Regarding the reverse plasticity limit $\Delta \theta_{r p}$, it is only affected by the local maximum thermo-elastic stress due to the difference in thermal expansion coefficients between the fiber and the matrix. Contours of thermoelastic stress, SDV40, under the reference thermal load $\Delta \theta_{0}=50^{\circ} \mathrm{C}$ are shown in Fig. 8 for all geometries. Taking into account the most critical location, where the computed values of SDV40 are $S D V 40_{\max }=171.2 \mathrm{MPa}$ for the cross sections in Fig. 8-c, e and SDV $40_{\max }=222.4 \mathrm{MPa}$ for the cross sections in Fig. 8-d, $\mathbf{f}$ it is evident that the same value in $\mathrm{SDV} 40_{\max }$ leads to the same value in reverse plasticity limit $\Delta \theta_{r p}$.

It is worth noting that the most critical locations in terms of thermo-elastic stress of both the square (Fig. 8-b) and the rectangular cross sections (Fig. 8-d, f) lie at the sharp corner on the interface 
between the fiber and matrix. In such circumstances, the solution does not converge to a specific value with increased mesh refinement and theoretically, the value of SDV40 ${ }_{\max }$ is infinite at the tip of the corner due to the singularity. As mentioned before, the reverse plasticity limit is only affected by the value of SDV40 $0_{\max }$. Hence, in presence of a singularity, the reverse plasticity limit is equal to zero. However, as no corner can be perfectly sharp, we rely upon the chosen mesh scheme to compute the reverse plasticity limits for both the square cross section and the rectangular cross section. Thus, the stresses at the singularity point, for the two mentioned cross sections, convergence to specific values for the adopted mesh scheme. Therefore we can define, a numerical thermo-elastic stress amplification factor $S A F_{\theta}$ (Junior et al., 2011) for the square cross section and the rectangular cross section. Table 3 reports a comparison of the $S A F_{\theta}$ factors between the fiber cross sections.

Unlike the reverse plasticity limit, the ratchet limit $\Delta \theta_{r t c}$ and the limit load $\sigma_{P l}$ are not affected by the local behavior as they are governed by a global failure mechanism (Giugliano and Chen, 2016). Therefore the sharp corner doesn't affect the results of these two limits.

On the basis of the previous outcomes, the attention has been paid only to the models $a, b, d$ and $f$ in Fig. 5 called circular, elliptical, square and rectangular, respectively.
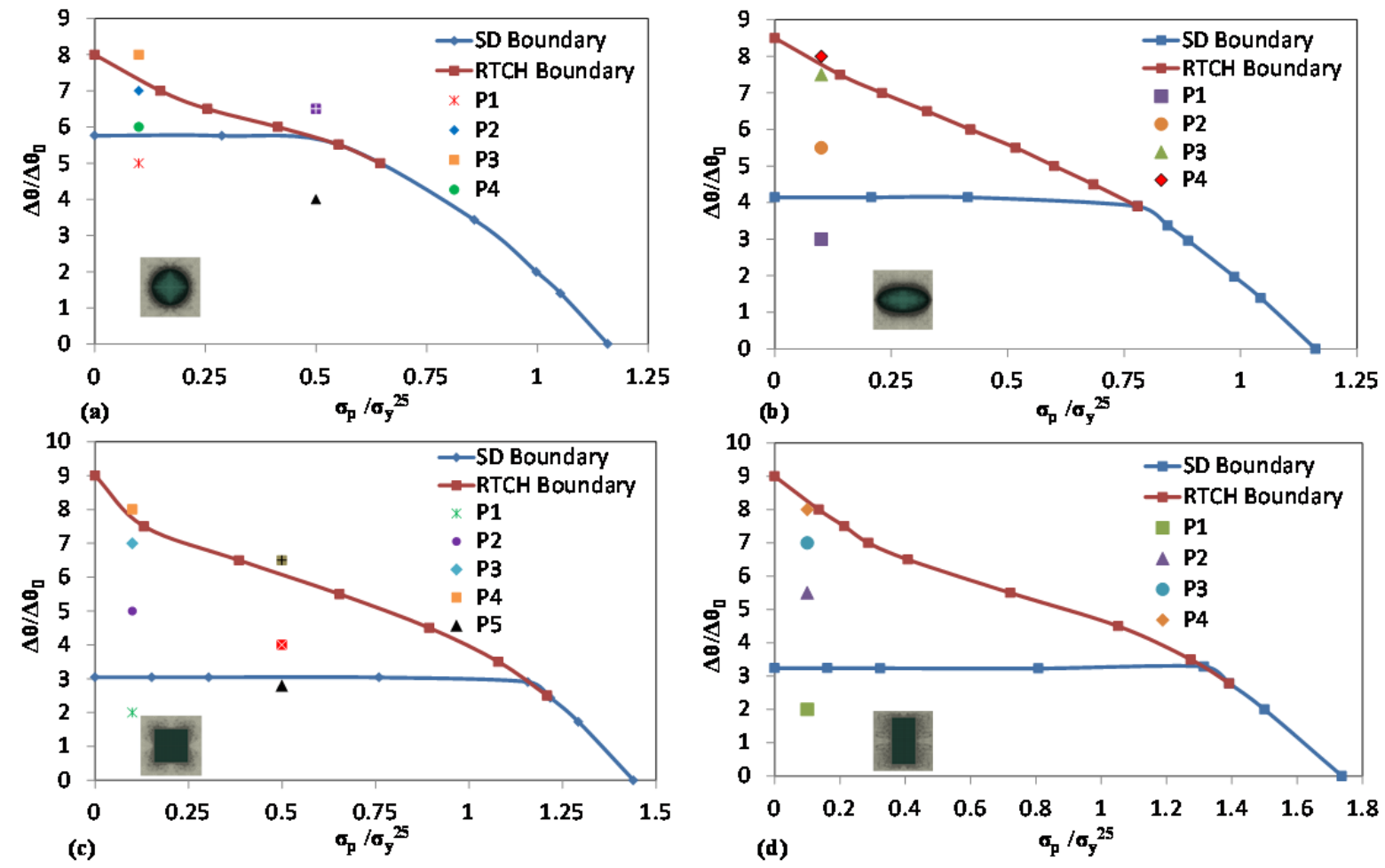

Fig. 9. Shakedown and ratchet limit boundaries for circular (a), elliptical (b), square (c), and rectangular (d) cross section models. 

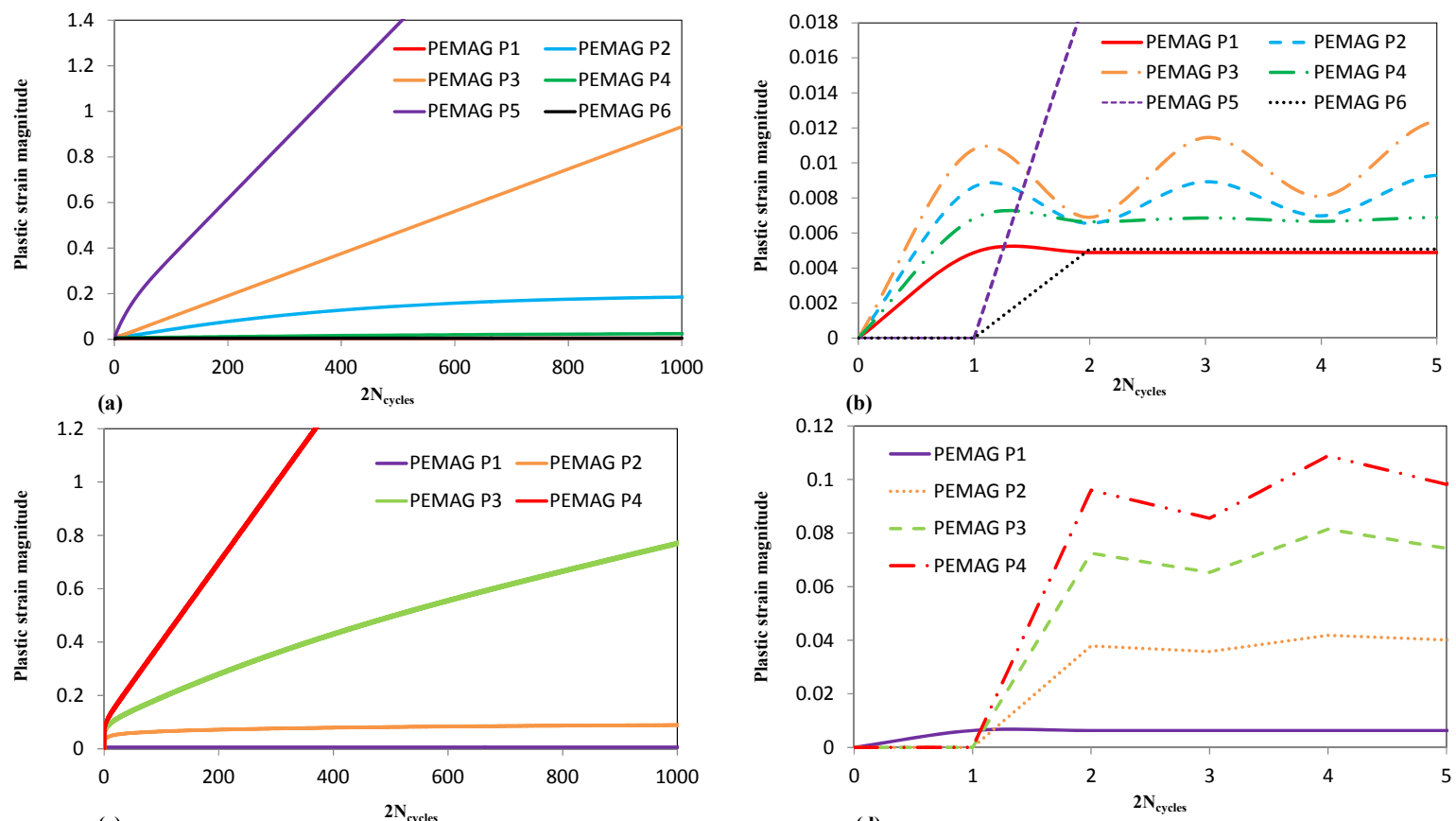

(d)
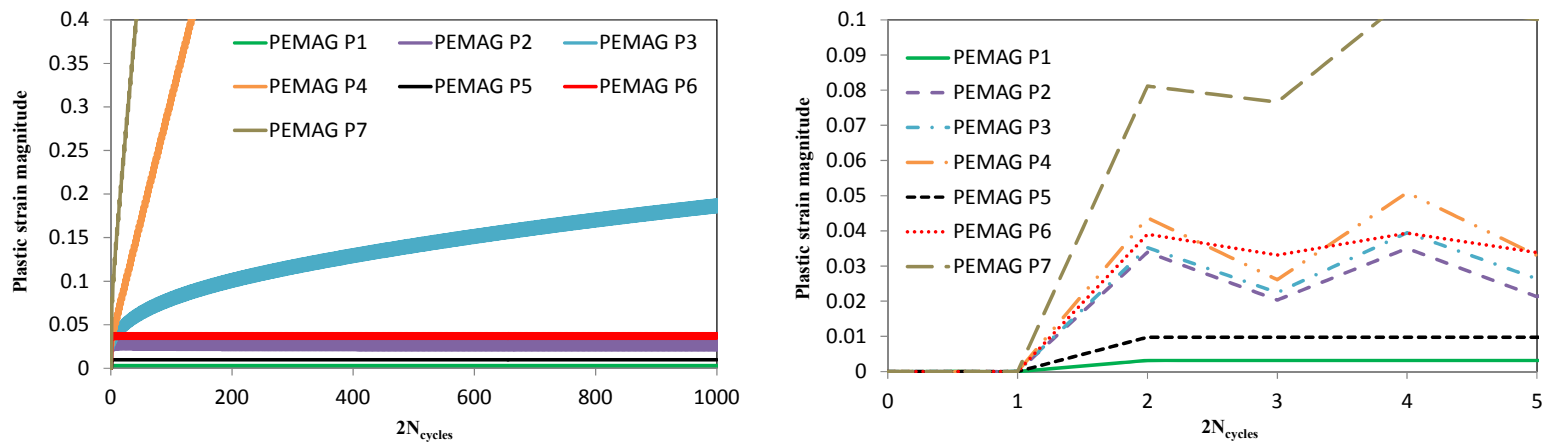

(e)
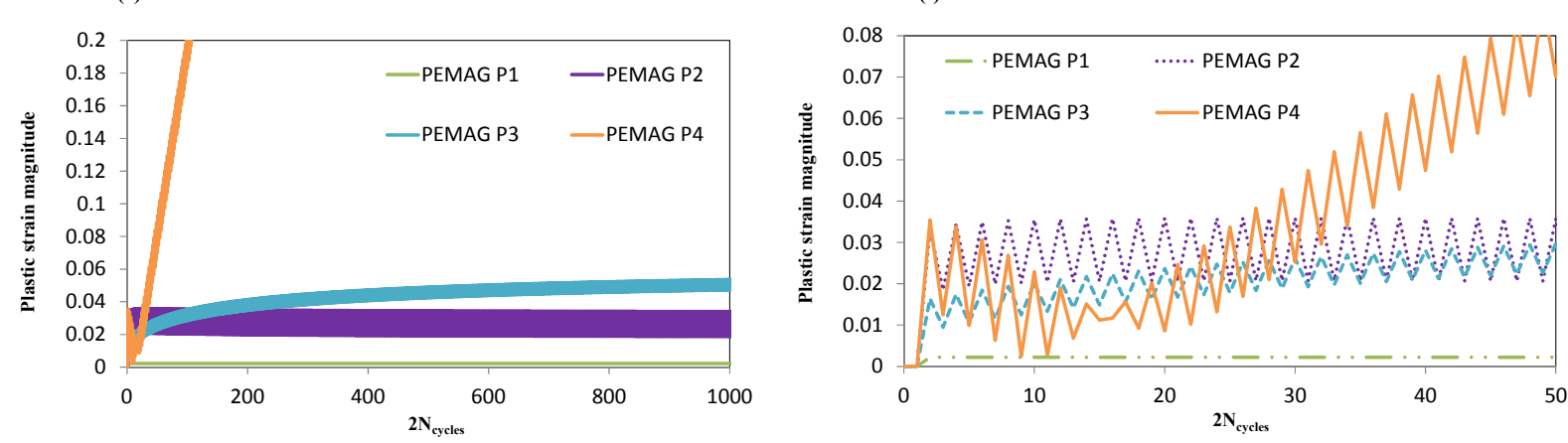

(g)

(h)

Fig. 10. History of plastic strain magnitude for the cyclic load points depicted in Fig. 9 and evaluated by Abaqus step-by-step analysis. (a) and (b) for the circular model, (c) and (d) for the elliptical model, (e) and (f) for the square model, $(\mathrm{g})$ and $(\mathrm{h})$ for the rectangular model.

Shakedown and ratchet limit boundaries are shown in Fig. 9 for the four models analyzed. In order to validate the obtained results by the LMM, incremental FEA (step-by-step analysis) for each of the load points depicted in Fig. 9-a, $\mathbf{b}, \mathbf{c}, \mathbf{d}$ has been employed. It can be observed from Fig. 10 that, as indicated by the Fig. 9-a, b, c, d, the cyclic load points displayed exhibit shakedown, reverse plasticity or ratcheting mechanism depending on whether they lie respectively in the shakedown region, reverse plasticity region or ratcheting region. Indeed, taking into account the circular model, it can be clearly seen that the load point $\mathrm{P} 1$ shows shakedown, the load point $\mathrm{P} 4$ shows reverse plasticity and the load point P5 exhibits ratcheting (Fig. 10-a, b). 
In order to better understand the variation of the plastic strain magnitude during the transient and steady state response, two different scales have been reported for each cross section in Fig. 10. 2 Ncycles stands for number of Abaqus steps that simulate the loading and unloading condition within each load cycle. All the analyses performed fully confirm the accuracy of the predicted limits. It is worth nothing that the LMM is capable of providing a full description of the interaction diagram. Instead the SBS analysis can only determine if for a single cyclic load point the structure is in shakedown, reverse plasticity or ratcheting. The relationship between the design limits calculated with the inelastic response of the structures accounts for the capability of the model analyzed to endure both fatigue damage and incremental plastic collapse.
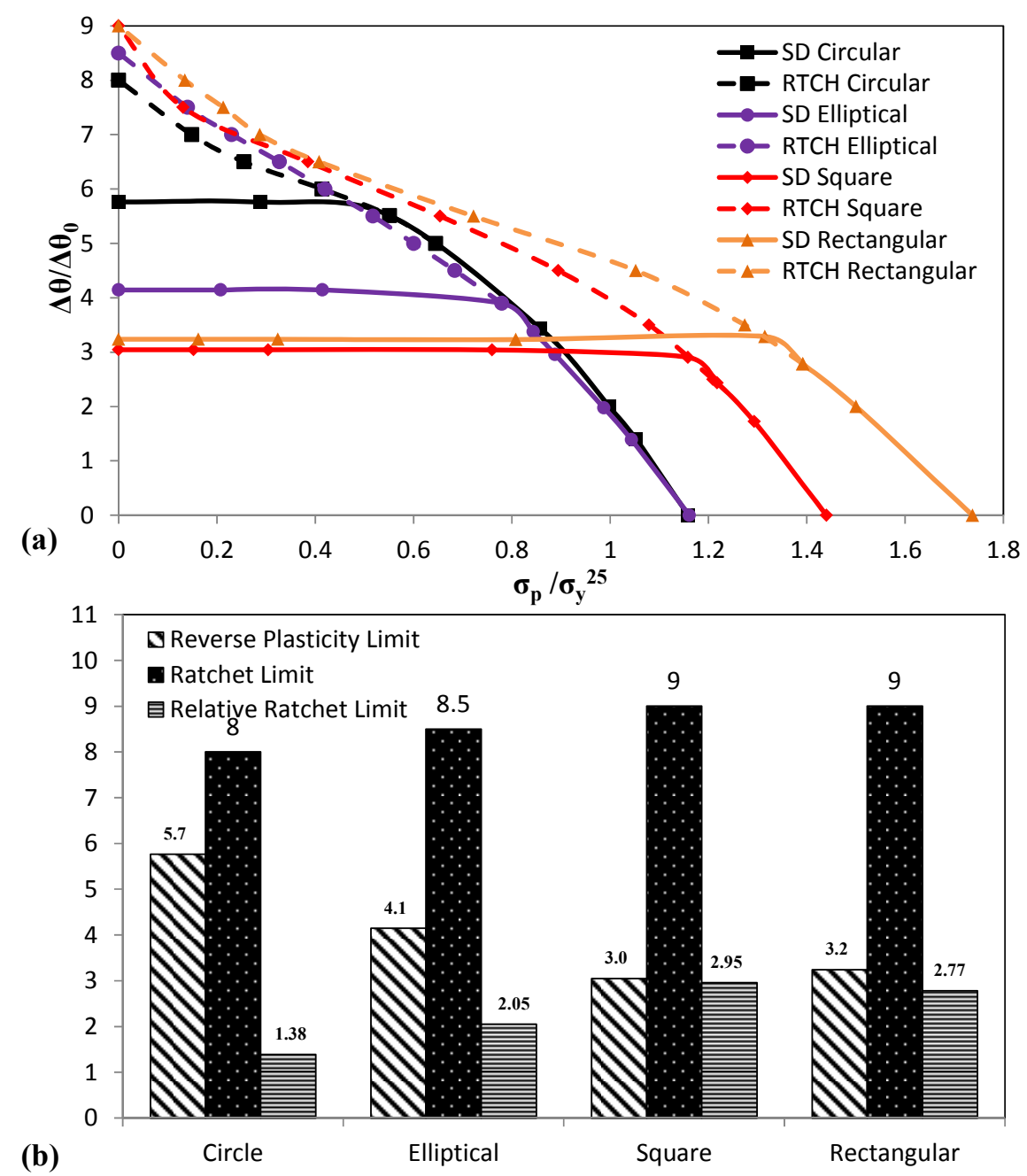

Fig. 11. Comparison between the four models (a), (b), (d) and (f) shown in Fig. 5 concerning (a) interaction diagrams; (b) critical design limits.

Fig. 11 shows the comparison of the critical design limits in the form of interaction diagram and bar chart. Since the reverse plasticity limit $\Delta \theta_{r p}$ is related to the LCF life whilst the ratchet limit $\Delta \theta_{r t c}$ is related to incremental plastic collapse of the structures (Chen and Ponter, 2005; Giugliano and Chen, 2016; Jansson and Leckie, 1992) it can be clearly seen that the circular cross section shows the highest capability to withstand cyclic thermal load conditions without exhibiting reverse plasticity and therefore it increases the LCF off-axis life of CFAMCs. Conversely, the circular model shows the lowest value of ratchet limit, viz, a reduced capability to avoid the incremental plastic collapse when a mechanical load is applied with a cyclic thermal load range 0 to $\Delta \theta_{\text {rtc }}$. 
The highest capability of the rectangular cross section to prevent the ratcheting mechanism is accounted for by the highest value of its ratchet limit. Similar results in terms of ratcheting strain are reported for particulate $\mathrm{SiC}_{\mathrm{p}} / 6061 \mathrm{Al}$ composites in (Kang et al., 2007) where it has been demonstrated that the spherical particulate shape is the weakest, whilst the cylindrical shape is the strongest with regard to the ratchet behavior. The relative ratchet limit $\Delta \theta_{r r t c}=\frac{\Delta \theta_{r t c}}{\Delta \theta_{r p}}$ shows instead the capacity to exhibit a lower magnitude of ratcheting strain per cycle once the load condition exceeds the ratchet threshold. In other words, if the load point analyzed lies in the ratcheting zone for all the cross section geometries considered in this paper, the lower is the relative ratchet limit, the lower is the ratcheting strain per cycle $\Delta \bar{\varepsilon}_{\text {rtc }}$ (Fig. 13-b).

\subsection{Plastic strain range and Ratcheting strain}

In ductile metallic materials such as steels and aluminum, microvoid nucleation and growth have been recognized as key mechanisms of damage. Therefore, damage initiation is assumed to be governed by the accumulated plastic strain (Khan et al., 2012). For a CFAMC, instead, mismatch in CTE between the constituents is the key parameter that influences in direct proportionality the thermal strains induced by thermo-mechanical fatigue loadings (Jansson and Leckie, 1992). The increase of reinforcement fraction volume cause further degradation in LCF response and induces the matrix to undergo large internal inelastic deformations, potentially leading to internal crack initiation. Fiber/Matrix debonding is also common, and gross macroscopic ratcheting deformation of the composite has been reported (Ahmadzadeh and Varvani-Farahani, 2015; Giugliano and Chen, 2016; Kang et al., 2007).

The influence of the fiber cross section geometry on the off-axis fatigue life response of CFAMCs is addressed by evaluating both the maximum plastic strain range $\Delta \bar{\varepsilon}_{p_{\max }}$ and the ratcheting strain per cycle $\Delta \bar{\varepsilon}_{\text {rtc }}$ (Chen and Ponter, 2005; Giugliano and Chen, 2016).

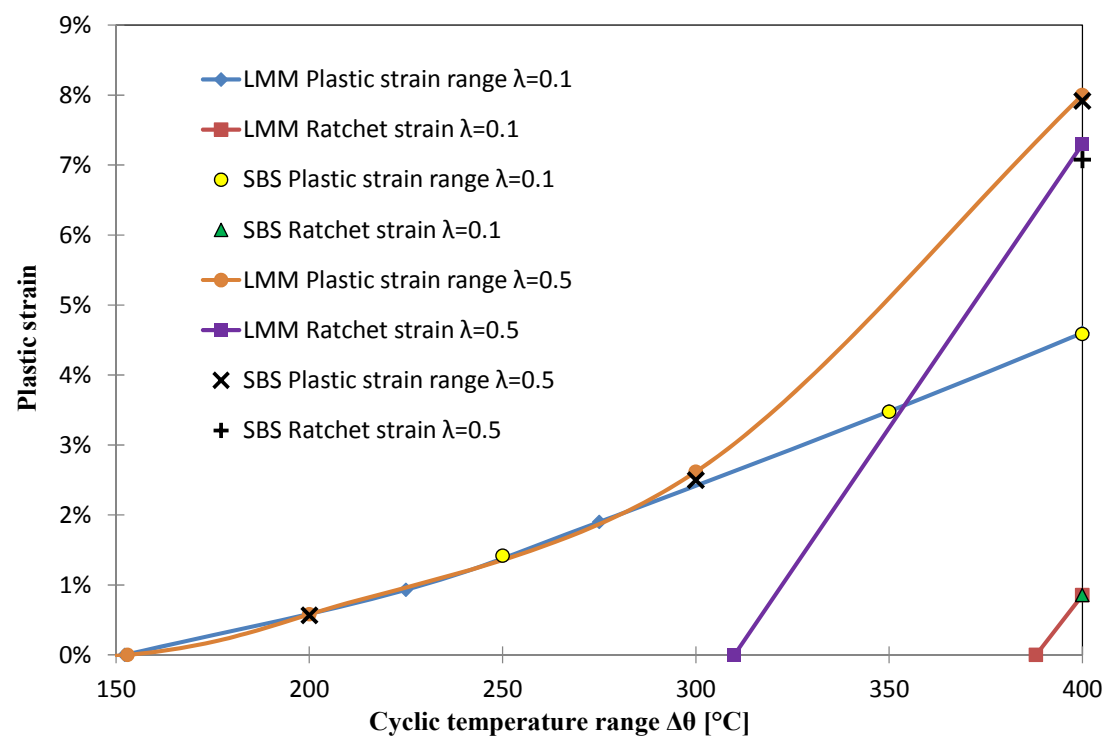

Fig. 12. Comparison between maximum plastic strain range $\Delta \bar{\varepsilon}_{p_{\max }}$ and ratcheting strains per cycle $\Delta \bar{\varepsilon}_{\text {rtc }}$ for the square model subjected to a wide range of varying cyclic thermal loads $\Delta \theta$ and two constant uniaxial macro-stress $\sigma_{p}=37.1 \mathrm{MPa}(\lambda=0.1)$ and $\sigma_{p}=185.5 \mathrm{MPa}(\lambda=0.5)$. 
The effect of the uniaxial macro stress magnitude $\sigma_{p}$ on both maximum plastic strain range $\Delta \bar{\varepsilon}_{p_{\max }}$ and ratcheting strains per cycle $\Delta \bar{\varepsilon}_{r t c}$ is shown in Fig. 12 for the square model, subjected to a combined effect of $\sigma_{p}$ and cyclic thermal loads $\Delta \theta$. It has previously been shown that the square shape exhibits the weakest behavior in terms of fatigue crack initiation and therefore much attention has been paid on it. The first outcome of Fig. 12 is that $\Delta \bar{\varepsilon}_{p_{\max }}$ is affected by the higher value of $\sigma_{p}$ only when the cyclic thermal loads amplitude $\Delta \theta$ is higher than $300^{\circ} \mathrm{C}$. Moreover, it can also be seen that $\Delta \bar{\varepsilon}_{\text {rtc }}$ is remarkably influenced by the magnitude of the mechanical load $\sigma_{p}$, which can be expected due to the relationship between the ratcheting mechanism and primary loads. It is known that plastic ratcheting can take place when a primary load is applied, giving a ratcheting direction (Ahmadzadeh and Varvani-Farahani, 2015; Giugliano and Chen, 2016).

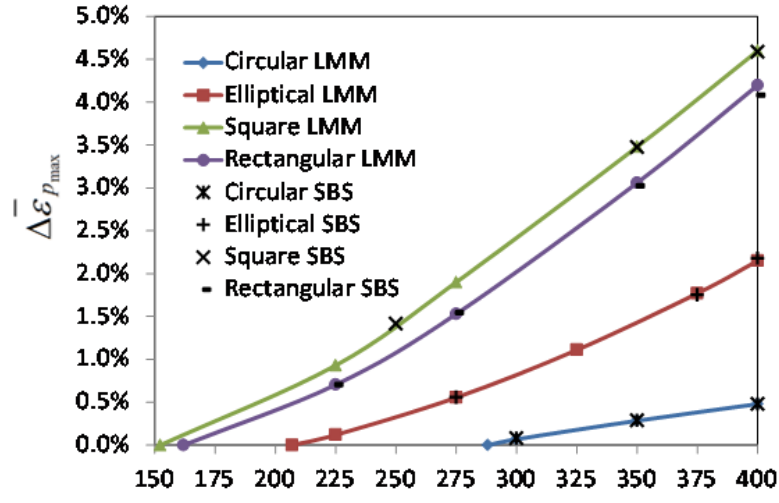

(a)

Cyclic temperature range $\left.\Delta \theta{ }^{\circ} \mathrm{C}\right]$

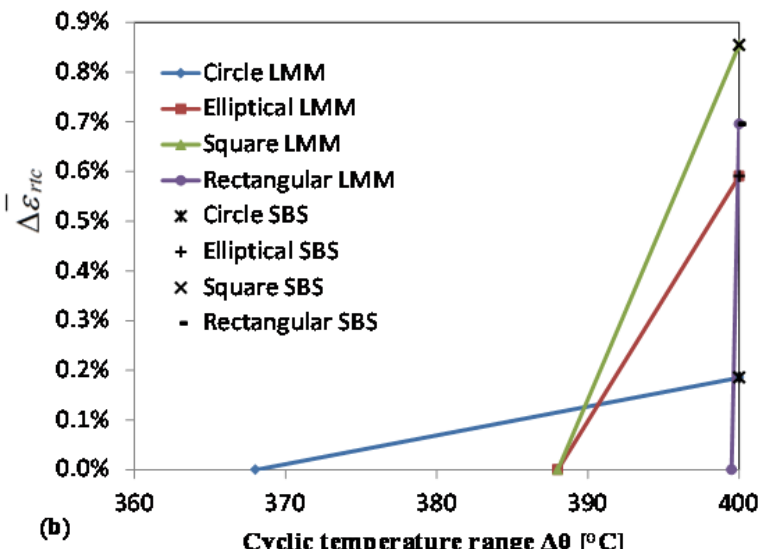

Fig. 13. Comparison between the four models analyzed, subjected to a wide range of varying cyclic thermal loads $\Delta \theta$ and constant $\sigma_{p}=37.1 \mathrm{MPa}$ of: (a) maximum plastic strain range $\Delta \bar{\varepsilon}_{p_{\max }}$; (b) ratcheting strains per cycle $\Delta \bar{\varepsilon}_{r t c}$.

Fig. 13 presents the calculated $\Delta \bar{\varepsilon}_{p_{\max }}$ and $\Delta \bar{\varepsilon}_{r t c}$ for the models analyzed subjected to varying cyclic thermal loads $\Delta \theta$ and constant mechanical load $\sigma_{p}=37.1 \mathrm{MPa}$. It can be observed that all the computed solutions of plastic strain range and ratcheting strain per cycle, verified by Abaqus matched the results of the LMM with an error less than 1\%. However, comparing with the LMM, the Abaqus step-by-step analysis involves much more significant computer effort to produce the same results.

By visually comparing the calculated $\Delta \bar{\varepsilon}_{p_{\max }}$ in Fig. 13-a, it is possible to account for the highest capacity of the circular cross section to endure LCF damage. This is mainly due to the higher reverse plasticity limit experienced by such cross section compared to the other geometries. Indeed, as mentioned in section 4.1, different cross section affects the stress amplification factor (Junior et al., 2011) and therefore the value of the reverse plasticity limit. Regarding the ratchet limit $\Delta \theta_{r t c}$, it expresses the capability of the structures to prevent incremental plastic collapse whilst the relative ratchet limit $\Delta \theta_{r r t c}$ gives an explanation on the magnitude of $\Delta \bar{\varepsilon}_{r t c}$ reported in Fig. 13-b. In fact, a lower value of $\Delta \theta_{\text {rrtc }}$ yield to a lower value of $\Delta \bar{\varepsilon}_{\text {rtc }}$ when the load condition considered is beyond 
the ratchet threshold. Taking into account the load point $\Delta \theta=400^{\circ} \mathrm{C}$ and $\sigma_{p}=37.1 \mathrm{MPa}$ where all the unit cells exhibit ratcheting, as reported in Fig. 13-b, it is possible to verify that the square model experiences the highest value of ratcheting strain per cycle as it has the highest value of the relative ratchet limit.

\subsection{Bearing load capacity and limit analysis}

To predict safe service conditions of structures made of heterogeneous materials under loads beyond the elasticity limit is a challenging task. Every material has certain strength, expressed in terms of stress or strain, beyond which the structure fractures or fails to carry the load. For heterogeneous materials, consisting of two or more phases, the determination of failure criteria is in fact one of the most important issues in the design process (Chen and Hachemi, 2014).

The capability of a structure to endure plastic collapse under static off-axis load is addressed by evaluating the limit load, i.e., the maximum load that a structure can safely carry. The upper bound approach (Carvelli et al., 1999; Ponter and Leckie, 1998a, b) has been employed on the unit cells reported in Fig. 5. Since an undamaged reinforcement - as well as a perfect bound between matrix and fiber - has been considered throughout this paper, the limit analysis carried out, accounts for the effects of the cross section geometry on the off-axis bearing load capacity by computing the ultimate load beyond which ductile failure occurs in the metal matrix.

The six models analyzed have been subjected to a uniaxial macro-stress $\sigma_{P}$ at room temperature. Matrix work-hardening has been neglected leading to a more conservative approach as reported in (Chen and Hachemi, 2014). All the results have been obtained by using the LMM shakedown analysis as a special case.
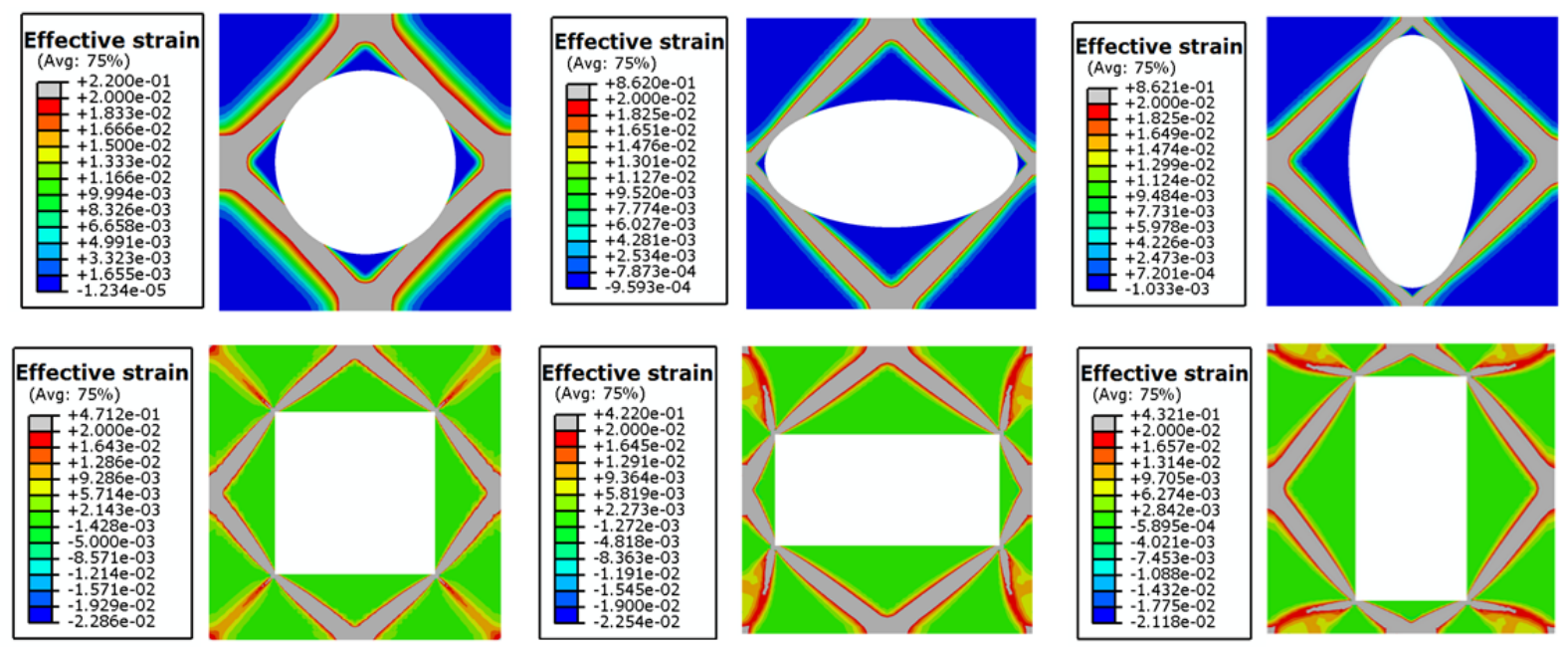

Fig. 14. Contours of effective strain for the models depicted in Fig. $\mathbf{5}$ and subjected to the limit load.

Fig. 14 shows the contours of effective strain due to the effects of the limit load applied transversally along the vertical edge as shown in Fig. 5. For the unit cells (b), (c), (e) and (f) depicted in Fig. 5, the computed limit load does not depend on the aspect ratios considered (1:2 and 2:1). More precisely, it is 1.161 for the elliptical cross sections and 1.737 for the rectangular cross sections. As a consequence, looking at the contour of the effective strain, an identical failure mechanism characterized by a set of slip bands that pass between the fibers, is observed for the unit cells with the same limit load. 


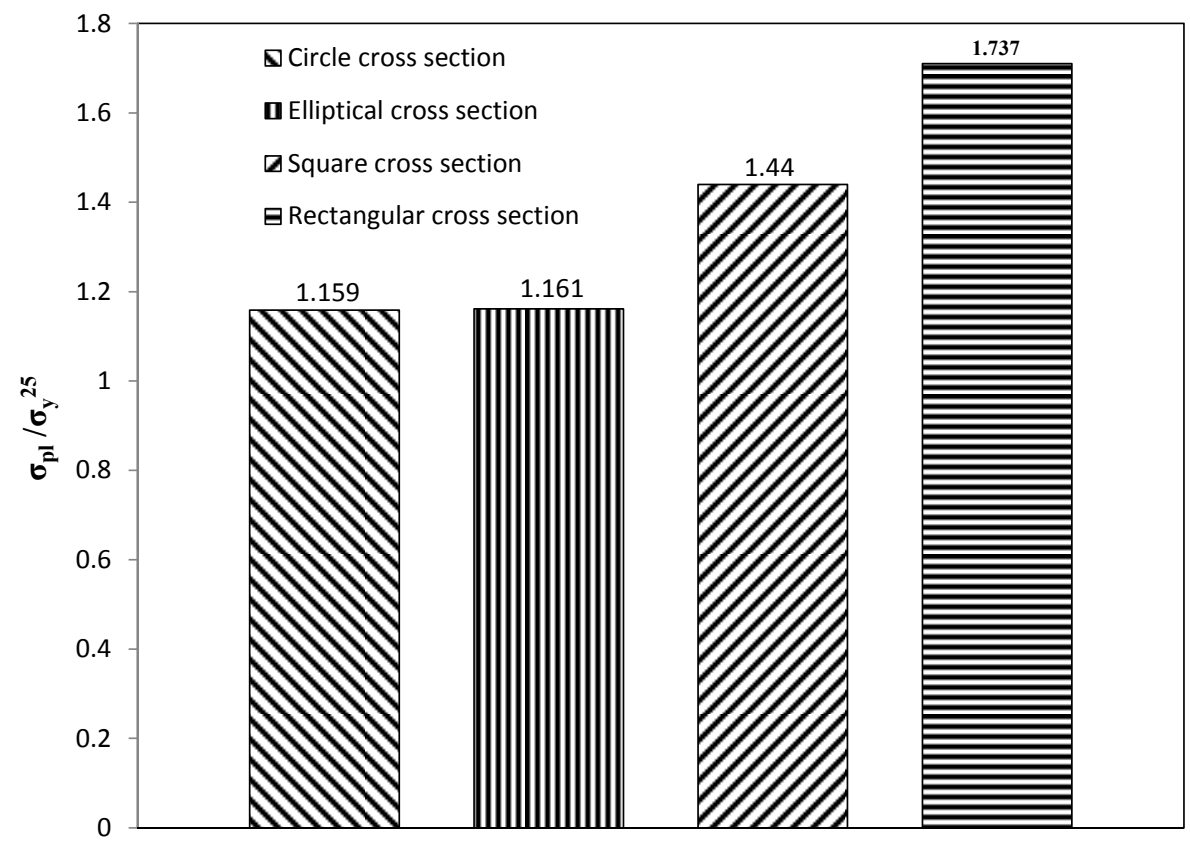

Fig. 15. Limit load $\sigma_{P l}$ normalized to the matrix yield stress $\sigma_{y}^{25}$ for the models (a), (b), (d), (f) shown in Fig. 5.

Fig. 15 provides the comparison of the limit load between the models shown in Fig. 5-a, b, d, $\mathbf{f}$ where $\sigma_{P l}$ is normalized by the yield stress of the matrix at $25^{\circ} \mathrm{C}$, which is equal to $371 \mathrm{MPa}$. It can be identified clearly from above that for the volume fraction considered equal to $30 \%$, the model with the rectangular cross section has the highest value compared with the others whilst the circular cross section and the elliptical cross section have approximately the same limit load. Equivalent results in the form of interaction diagram are shown in Fig. 11-a for $\Delta \theta=0^{\circ} \mathrm{C}$.

As reported in (Giugliano and Chen, 2016) it is possible to evaluate a reference value of the fiber fraction volume $V f_{\text {ref }}$ beyond which the composite enhances its limit load. For a fiber volume fraction less than the reference value, the composite limit load $\sigma_{P l}$ is equal to the limit load of the matrix alone $(V f=0 \%)$, i.e. the fiber doesn't enhance the strength of the composite. Instead, when the fiber volume fraction is higher than $V f_{\text {ref }}$, the fiber improves the limit load as shown in our companion paper where, the reference volume for the circular cross section is almost equal to $40 \%$. Therefore, for $V f=30 \%$, the fiber enhances the limit load only for the square geometry and the rectangular geometry, where the reference volume is less than $30 \%$. Thus, we derive the following inequalities:

$$
V f_{\text {ref }}^{\text {circular }}>30 \%>V f_{\text {ref }}^{\text {square }}>V f_{\text {ref }}^{\text {rectan gular }} \text {. }
$$

(2)

For the composite with the elliptical cross section, the reference fiber volume fraction is almost equal to $V f_{\text {ref }}^{\text {circular }}$ which is $40 \%$, and the maximum possible fiber volume ratio is $39.27 \%$ as discussed in section 3. Therefore any increase of fiber volume will not enhance the limit load for the defined fiber aspect ratio $(2: 1)$. 


\section{CONCLUSIONS}

This work focusses on the effects of the cross section fiber geometry along with temperature dependent matrix yield stress on CFAMCs' cyclic plastic response using computational micromechanics. The results are obtained by using a direct method approach, and the LMM has been used for this paper. Incremental FEA has been carried out in order to provide a validation of the LMM's results in terms of both accuracy and computational cost.

As expected, the thermal degradation of the yield stress leads both limits $\Delta \theta_{r p}$ and $\Delta \theta_{r t c}$ to have a lower value compared with the same model where the yield $\sigma_{y}$ has been kept constant and equal to $\sigma_{y}^{(25)}$. It has also been shown that the aspect ratios considered (1:2 and 2:1) for, the elliptical (Fig. 5-b and Fig. 5-c) and rectangular models (Fig. 5-e and Fig. 5-f) with $V f=30 \%$, doesn't affect the results in terms of limit load, reverse plasticity limit and ratchet limit.

The evaluation of the critical design limits demonstrates the capability of the circular cross section to enhance the low cycle fatigue life whilst the square cross section exhibits the weakest capacity to prevent LCF damage. In fact, the highest value of $\Delta \theta_{r p}$ has been calculated in the circular model whilst the lowest value has been calculated in the square model. This leads to a lower values of the plastic strain ranges $\Delta \bar{\varepsilon}_{p_{\max }}$ for the circular model compared to the square model. Regarding the ratchet limit $\Delta \theta_{\text {rtc }}$, the rectangular cross section and the square cross section exhibit the highest value and therefore a higher capability to prevent incremental plastic collapse. However, by evaluating the ratcheting strain per cycle it has demonstrated that the magnitude of $\Delta \bar{\varepsilon}_{\text {rtc }}$ depends on the relative ratchet limit $\Delta \theta_{r r t c}$. Therefore the circle cross section exhibited lower values of $\Delta \bar{\varepsilon}_{\text {rtc }}$ when the load conditions exceed the ratchet boundary for all the models.

The off-axis bearing load capability has been accounted for by evaluating the limit load $\sigma_{P l}$ for the models analyzed. The unit cell with the rectangular cross section has got the highest value of $\sigma_{P l}$ whilst the cell with the circular cross section has got the lowest value. It has been demonstrated that the rectangular cross section and the square cross section need a lower reinforcement fraction volume compared to the circular cross section for enhancing the capability to withstand off-axis constant mechanical loading at room temperature.

\section{ACKNOWLEDGEMENTS}

The authors gratefully acknowledge the support of the University of Strathclyde and Royal Academy of Engineering during the course of this work.

\section{REFERENCES}

Ahmadzadeh, G., Varvani-Farahani, A., 2015. Ratcheting prediction of Al 6061/SiCP composite samples under asymmetric stress cycles by means of the Ahmadzadeh-Varvani hardening rule. Journal of Composite Materials, 0021998315604037.

Böhm, H.J., Rammerstorfer, F.G., Weissenbek, E., 1993. Some simple models for micromechanical investigations of fiber arrangement effects in MMCs. Computational materials science 1, 177-194. 
Bonnen, J., You, C., Allison, J., Jones, J., 1990. Fatigue properties of SiC particulate reinforced Al-alloys, Proceeding of 4th International Conference on Fatigue,(ed. Kitagava, H., and Tanaka, T.), Honolulu, pp. 887-892.

Carvelli, V., Maier, G., Taliercio, A., 1999. Shakedown analysis of periodic heterogeneous materials by a kinematic approach. Mech. Eng. Strojnicky C asopis 50, 229-240.

Chen, H., 2010. Lower and upper bound shakedown analysis of structures with temperaturedependent yield stress. Journal of Pressure Vessel Technology 132, 011202.

Chen, H., Ponter, A.R., 2005. On the behaviour of a particulate metal matrix composite subjected to cyclic temperature and constant stress. Computational materials science 34, 425441.

Chen, H., Ponter, A.R., 2010. A direct method on the evaluation of ratchet limit. Journal of Pressure Vessel Technology 132, 041202.

Chen, H., Ure, J., Tipping, D., 2014. Integrated structural analysis tool using the Linear Matching Method part 2-Application and verification. International Journal of Pressure Vessels and Piping 120, 152-161.

Chen, M., Hachemi, A., 2014. Progress in plastic design of composites, Direct Methods for Limit States in Structures and Materials. Springer, pp. 119-138.

Corbin, S., Wilkinson, D., 1994. Low strain plasticity in a particulate metal matrix composite. Acta metallurgica et materialia 42, 1319-1327.

Devireddy, S.B.R., Biswas, S., 2014. Effect of fiber geometry and representative volume element on elastic and thermal properties of unidirectional fiber-reinforced composites. Journal of Composites 2014.

Giugliano, D., Chen, H., 2016. Micromechanical modeling on cyclic plastic behavior of unidirectional fiber reinforced aluminum matrix composites. European Journal of Mechanics - A/Solids 59, 155-164.

Han, N., Wang, Z., Sun, L., 1995. Effect of reinforcement size on low cycle fatigue behavior of $\mathrm{SiC}$ particle reinforced aluminum matrix composites. Scripta metallurgica et materialia 33, 781-787.

Hashin, Z., 1983. Analysis of composite materials - a survey. Journal of Applied Mechanics 50, 481-505.

Hibbitt, K., 1997. ABAQUS: User's Manual. Hibbitt, Karlsson \& Sorensen, Incorporated. Jansson, S., Leckie, F., 1992. Mechanical behavior of a continuous fiber-reinforced aluminum matrix composite subjected to transverse and thermal loading. Journal of the Mechanics and Physics of Solids 40, 593-612.

Junior, P.C.P., de Silva Bussamra, F.L., Arakaki, F.K., 2011. Finite element procedure for stress amplification factor recovering in a representative volume of composite materials. Journal of Aerospace Technology and Management 3, 239-250.

Kang, G., Dong, C., Guo, S., 2007. Finite element analysis for uniaxial time-dependent ratcheting of $\mathrm{SiC} \mathrm{P} / 6061 \mathrm{Al}$ composites at room and high temperatures. Materials Science and Engineering: A 458, 170-183.

Khan, S., Kintzel, O., Mosler, J., 2012. Experimental and numerical lifetime assessment of Al 2024 sheet. International Journal of Fatigue 37, 112-122.

Llorca, J., 1994. A numerical study of the mechanisms of cyclic strain hardening in metalceramic composites. Acta metallurgica et materialia 42, 151-162.

Llorca, J., Needleman, A., Suresh, S., 1991. An analysis of the effects of matrix void growth on deformation and ductility in metal-ceramic composites. Acta Metallurgica et Materialia 39, 2317-2335.

Llorca, J., Suresh, S., Needleman, A., 1992. An experimental and numerical study of cyclic deformation in metal-matrix composites. Metallurgical Transactions A 23, 919-934. 
Lytwyn, M., Chen, H.F., Ponter, A.R.S., 2015. A generalised method for ratchet analysis of structures undergoing arbitrary thermo-mechanical load histories. International Journal for Numerical Methods in Engineering 104, 104-124.

Ponter, A., Leckie, F., 1998a. Bounding properties of metal-matrix composites subjected to cyclic thermal loading. Journal of the Mechanics and Physics of Solids 46, 697-717.

Ponter, A., Leckie, F., 1998b. On the behaviour of metal matrix composites subjected to cyclic thermal loading. Journal of the Mechanics and Physics of Solids 46, 2183-2199.

Sasaki, M., Lawson, L., Meshii, M., 1994. Low-cycle fatigue properties of a SiC whiskerreinforced 2124 aluminum alloy. Metallurgical and Materials Transactions A 25, 2265-2274. Srivastava, V., Gabbert, U., Berger, H., Singh, S., 2011. Analysis of particles loaded fiber composites for the evaluation of effective material properties with the variation of shape and size. International Journal of Engineering, Science and Technology 3.

Srivatsan, T., Auradkar, R., 1992. Effect of silicon carbide particulate on cyclic plastic strain response characteristics and fracture of aluminium alloy composites. International journal of fatigue 14, 355-366.

Srivatsan, T., Prakash, A., 1994. Effect of particulate silicon carbide on cyclic strain resistance and fracture behavior of X2080 aluminum alloy metal matrix composites. Engineering fracture mechanics 49, 751-772.

Surappa, M., 2003. Aluminium matrix composites: Challenges and opportunities. Sadhana 28, 319-334.

Suresh, S., Mortensen, A., Needleman, A., 1993. Fundamentals of MMCs. ButterworthHeinemann, Boston.

Ure, J., Chen, H., Tipping, D., 2013. Calculation of a lower bound ratchet limit part 2 Application to a pipe intersection with dissimilar material join. European Journal of Mechanics - A/Solids 37, 369-378.

Ure, J., Chen, H., Tipping, D., 2014. Integrated structural analysis tool using the linear matching method part 1-Software development. International Journal of Pressure Vessels and Piping 120, 141-151.

Ure, J.M., Chen, H., Tipping, D., 2012. Development and implementation of the ABAQUS subroutines and plug-in for routine structural integrity assessment using the Linear Matching Method, SIMULIA Community Conference 2012,(Formerly the ABAQUS Users Conference).

Uygur, I., Külekci, M.K., 2002. Low Cycle Fatigue Properties of 2124/SiC_\{p\} Al-Alloy Composites. Turkish Journal of Engineering and Environmental Sciences 26, 265-274.

Xu, D., Schmauder, S., Soppa, E., 1999. Influence of geometry factors on the mechanical behavior of particle-and fiber-reinforced composites. Computational materials science 15 , 295-301. 